\title{
An Overview of Thermal Necrosis: Present and Future
}

\author{
Mohamed Mediouni (1 $\left.{ }^{* \prime}\right)$, Theodore Kucklick (2'), Sébastien Poncet (1'), Riadh \\ Madiouni (3), Amine Abouaomar (1'), Henning Madry (4'), Magali Cucchiarini (4'), \\ Bohdan Chopko (5'), Neil Vaughan (6'), Manit Arora (7'), Kemal Gökkuş (8'), Mario \\ Lozoya lara (9'), Lorenlay Paiva Cedeño (10'), Alexander Volosnikov (11'), Mohamed \\ Hesmati (12'), Kevin Ho (13')
}

1. Independent researcher, 1420, rue laterierre, Sherbrooke, Québec, J1K2R2

Canada

2. President and CTO Cannuflow Inc. 489 Division Street, Campbell, CA, USA

3. University of Paris-Est Créteil, 122 rue Paul Armangot, 94400 Vitry sur Seine, France

4. Saarland University Medical Center, Homburg, Germany

5. Ohio Health Mansfield Hospital, USA

6. Department of Computer Science, University of Chester, United Kingdom

7. Department of Orthopaedics and Sports Medicine, Fortis Hospital, Chandigarh, India

8. Memorial Antalya (Zafer Mah. Yıldırım Beyazıt Cad. No: 91 Kepez), Antalya, Turkey

9. Hospital Santa Rita, Mexico

10. Francisco de Miranda experimental university, Venezuela

11. Federal State Budgetary Institution, Russian Ilizarov Scientific Center,

Restorative Traumatology and Orthopaedics of Ministry of HealthcareKurgan,

Kurgan Region, Russia

12. Tehran University medical of sciences, Iran

13. University of Western Australia, Perth, Australia

(') Equal contributors

(*) corresponding author: Mohamed.Sherbrooke@gmail.com 


\begin{abstract}
Introduction: Many orthopaedic procedures require drilling of bone, especially fracture repair cases. Bone drilling results in heat generation due to the friction between the bone and the drill bit. A high level heat generation kills bone cells. Bone cell death results in resorption of bone around bone screws.

Materials and methods: Many points of view of orthopaedists and neurosurgeons based upon on previous practices and clinical experience are presented.

Results: Several potential complications are discussed and highlighted that lead to thermal necrosis.

Discussion: Even in the face of growing evidence as to the negative effects of heatinduction during drilling, simple and effective methods for monitoring and cooling in realtime are not in widespread usage today. For that purpose, we propose some suggestions for the future of bone drilling, taking note of recent advances in autonomous robotics, intelligent systems, and computer simulation techniques.
\end{abstract}

Conclusions: These advances in prevention of thermal necrosis during bone drilling surgery are expected to reduce the risk of patient injury and costs for the health service.

Keywords: Osteonecrosis, drilling, water jet, finite element analysis, machine-learning. 


\section{Osteonecrosis: view from above}

Many orthopaedic procedures require drilling of bone, especially cases of fracture and cartilage repair. The success of such surgical operation depends on the large part on the quality and performance of the drilling procedure. Bone drilling results in heat generation due to the friction between the bone and the drill bit [1, 2]. A high level of heat generation kills bone cells. In addition, it leads to the loss of blood supply to a particular bone at or around the joint and ischemia of bone cells. This phenomenon is known as thermal osteonecrosis $[3,4]$.

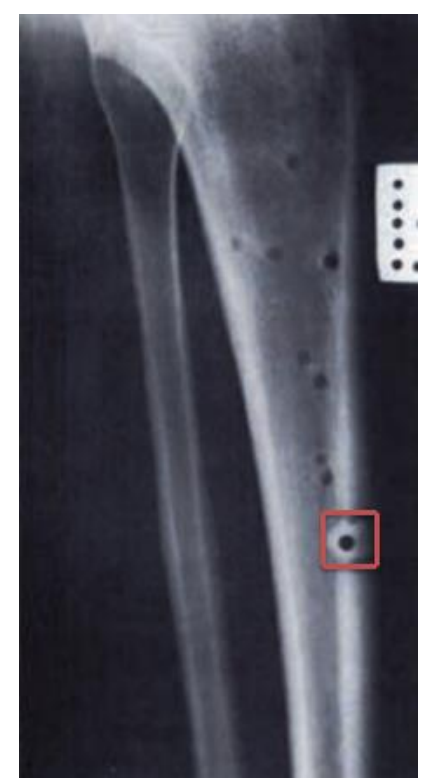

Figure 1. The area around the hole is a ring sequestrum, that is dead bone caused by severe thermal injury during drilling (extracted from [5])

Osteonecrosis affects around 20,000 adults every year in the US and progresses through stages from an initial painless stage with underlying microscopic bone damage to more painful and arthritic stages with macroscopic changes in bone structure and vitality. Osteonecrosis as a real clinical problem, independently of its origin, will generate partial or permanent destruction of the regenerative capacity of the bone tissue and articular cartilage, which translates into functional impairment and the patient's joint mobility, finally leading to a probable functional disability. 
Generally, thermal necrosis occurs soon after surgery, but Ishida et al. [6] present a rare case of a patient with osteocutaneous thermal necrosis associated with simultaneous tibial corrective osteotomy and total knee arthroplasty (TKA). In this particular case, the cutaneous blister was apparently more than 2 weeks after the surgery.

Osteonecrosis potentially results in catastrophic failures of orthopaedic screw-bone constructs and sometimes even promotes infection [7]. In summary, the essential shortcomings of buttress threads include the risk of stripping, screw loosening, induction of stress risers, bone micro-fracturing, heat necrosis, with subsequent failure of fixation and risk of creating fracture nonunions and malunions [8]. In the field of articular cartilage repair, bone marrow stimulation is often performed using either a surgical twist drill bit or a Kirschner wire to introduce defined holes in the subchondral bone plate following meticulous removal of the calcified cartilage layer at the bottom of the defect. The subchondral bone plate is penetrated by the cutting tip of the instrument at a high speed [9]. Because of the heat generation during cartilage and bone drilling, the chondrocytes and osteoblasts are at risk. The use of a coolant such as saline during drilling is well established, as it avoids such heat necroses [9]. In the study of Chen et al. [10], drilling with cooling did not cause greater osteocyte death than microfracture at one day post-operatively. Drill speed and drill diameter are other factors affecting the increase in temperature as a result of the bone drilling process $[10,11]$.

The mechanism of action for thermal necrosis of tissue is well known and well documented. Immediate effects include cellular membrane disruption and blood flow coagulation, whereas delayed effects stem from induction of apoptosis pathways [12]. Elevated temperatures above $45^{\circ} \mathrm{C}$ coagulate blood and cause ischemic or infarction loss of blood flow to tissues. This thermal effect is widely used for coagulation hemostasis, and to ablate undesired tissue such as hyperplasia or tumors. eg: Radiofrequency Interstitial Tissue Ablation (RITA) "Starburst" RF electrode in liver (Angiodynamics), Trans Urethral Needle Ablation (TUNA) RF needle ablation in prostate (Meredi Therapeutics) or High Frequency Focused Ultrasound (HIFU) focused ultrasound to produce heat (Kona Medical). Excessive cold can also damage tissue and is commonly used to ablate unwanted tissue as well, e.g cryoablation, atrial fibrillation (also called AFib or AF), prostate and vertebral body tumors (Boston Scientific, Sanarus, Atricure, Endocare). The preservation 
of tissue, therefore, requires that tissue is kept at a stable physiologic temperature- i.e. neither too hot or too cold. No tissue can tolerate heat above $45^{\circ} \mathrm{C}$ well and coagulation leads to tissue death. Some tissues such as nerves are especially sensitive to both heat and cold. In fact, it is a well-known tenet of skull base neurosurgery that even minute increases in brain temperature during bipolar coagulation can cause catastrophic collateral brain damage. In the brainstem region, catastrophic perforator artery and vein occlusion can result from inadvertent current spread from the tips of bipolar forceps [66,67]. In multiple models of ischemic stroke, bipolar coagulation to both arteries and veins leads to vessel thrombosis and neuronal loss due to the resultant infarction of tissue $[68,69]$. To the best our knowledge, no commercially available thermal injury mitigation systems are available for use during brain surgery despite the risks that patients are exposed to on a daily basis.

Cartilage is non-vascular but sensitive to heat and has very limited ability to regenerate in response to thermal injury. However, to get warmed or cooled sterile saline in the orthopaedic, a number of uncontrolled methods are used, from placing saline bags either in a refrigerator or in a towel warmer, sometimes with disastrous results [13]. Heating above $45^{\circ} \mathrm{C}$ and uncontrolled cold on nerve tissue can both produce severe complications, and a method for maintaining physiologic temperature would be desirable.

The soft tissue damage, as well as, bone injury may occur during the reaming process [7]. These include deep infection, patellar tendon injury and damage to intra-articular structures [14]. In addition, reaming has been associated with an increase in the core temperature of the tibial shaft, this might alter the endosteal architecture and blood supply leading to catastrophic complication of thermal osteonecrosis. Such a complication ultimately might lead to delayed union or non-union of the fracture site [15].

The main challenge for bone drilling is to maintain the temperature below the threshold limit, which is $47^{\circ} \mathrm{C}$ in case of human bone [16]. In order to control the drilling damage at the time of bone drilling. The study of Singh et al. [17] focuses on the optimization of drilling parameters for surface roughness and material removal rate using Taguchi optimization. In the study of Singh et al. [18], a comparison was carried between conventional and a loose abrasive unconventional bond drilling technique. The authors indicate that drilling during conventional bone drilling can leads to problems such as crack 
initiation and thermal necrosis. The rise in temperature during bone drilling is the result of different drilling parameters. Vibrational drilling was observed as a helping tool to control the thermal damage in bone drilling [19].

\section{Current Techniques for Prevention of Thermal Necrosis}

\subsection{Drill Parameters}

Several studies have aimed at establishing criteria to identify the typical temperature rise and the corresponding duration that would cause thermal necrosis during bone drilling [ 20 , 21, 22, 23]. The most important drilling parameters on bone temperature rise are: drilling depth and cortical bone thickness (see table 1), bone density [27], drilling speed (see table 2), drill diameter (see table 3), axial force, i.e. pressure applied to the drill [28], use of graduated versus one-step drilling [29,30]. Hsu et al. [17] developed a modular mechatronic system to prevent excessive protrusion of the drill bit.

Table 1. Previous studies on drilling depth and cortical bone thickness influencing temperature

\begin{tabular}{|c|l|}
\hline References & \multicolumn{1}{c|}{ Results } \\
\hline Eriksson et al. [20] & $\begin{array}{l}\text { The temperature measured for different species (rabbit, dog, and } \\
\text { human). The variations of temperature were due to the difference } \\
\text { in the mean cortical thickness. }\end{array}$ \\
\hline $\begin{array}{c}\text { Hillery and Shuaib } \\
\text { [31] }\end{array}$ & $\begin{array}{l}\text { The temperature was higher for the bovine bone }(7 \mathrm{~mm}-9 \mathrm{~mm}) \text { as } \\
\text { compared to human bones }(3 \mathrm{~mm}-5 \mathrm{~mm})\end{array}$ \\
\hline $\begin{array}{c}\text { Wiggins and } \\
\text { Malkin [32] }\end{array}$ & $\begin{array}{l}\text { The temperature produced during drilling is proportional to the } \\
\text { drilling depth. }\end{array}$ \\
\hline $\begin{array}{c}\text { Cordioli and } \\
\text { Majzoub [33] }\end{array}$ & $\begin{array}{l}\text { The temperature increase at } 8 \mathrm{~mm} \text { depth as compared to } 4 \mathrm{~mm} \\
\text { depth regardless of the drill diameter and the presence of cooling }\end{array}$ \\
\hline Kalidindi [34] & $\begin{array}{l}\text { The increase of temperature with depth is due to the increase in the } \\
\text { contact time between the workpiece and the drilling tool. }\end{array}$ \\
\hline
\end{tabular}

Table 2. Previous studies on the speed of drill influencing temperature 


\begin{tabular}{|c|l|}
\hline References & \multicolumn{1}{|c|}{ Results } \\
\hline Hirsch [35] & $\begin{array}{l}\text { * The increasing the rotational speed from 345 rpm to 2900 rpm } \\
\text { don't have any influence in the temperature during drilling for } \\
\text { human cadaveric. } \\
\text { * The increasing the force from 19.6 N to 117.6 N along with the } \\
\text { same drill speeds concluded that the temperature above 50 C } \\
\text { decreases as the applied load increases. }\end{array}$ \\
\hline $\begin{array}{c}\text { Augustin et al. } \\
\text { [36] }\end{array}$ & $\begin{array}{l}\text { The temperature during drilling decreases as the feed rate } \\
\text { increases. }\end{array}$ \\
\hline Hillery and Shuaib & $\begin{array}{l}\text { The temperatures decrease during bone drilling with increasing } \\
\text { drill speed from 400 rpm to 2000 rpm with a drill diameter of 3.2 } \\
\text { mm }\end{array}$ \\
\hline Sharawy et al. [37] & $\begin{array}{l}\text { The time of drilling is needed to return to the initial temperature } \\
\text { decreases as the drilling speed increases. }\end{array}$ \\
\hline Boyne [38], Moss & $\begin{array}{l}\text { The high speed drilling could cause less noxious effect to the bone } \\
\text { than the low speed drilling }\end{array}$ \\
\hline [yer et al. [40] & $\begin{array}{l}\text { The temperature generated in vivo during osteotomy preparation } \\
\text { at low (2000 rpm), intermediate (30,000 rpm), and high (400,000 } \\
\text { rpm) speeds and observed an inverse relationship between drill } \\
\text { speed and heat generated. }\end{array}$ \\
\hline Reingewirtz [41] & $\begin{array}{l}\text { The temperature is positively correlated with the speed in the range } \\
\text { of 400 rpm-7000 rpm and negatively correlated with speed above } \\
\text { 700 rpm-24,000 rpm }\end{array}$ \\
\hline
\end{tabular}

Table 3. Previous studies on drill diameter influencing temperature

\begin{tabular}{|c|l|}
\hline References & \multicolumn{1}{c|}{ Results } \\
\hline Kalidindi [34] & $\begin{array}{l}\text { The temperature increases with increasing drill diameter. The } \\
\text { temperature was measured with three different drills of diameters } \\
2,3.5 \text { and } 4.3 \mathrm{~mm} \text { at the same speed. }\end{array}$ \\
\hline $\begin{array}{c}\text { Augustin et al. } \\
{[36]}\end{array}$ & $\begin{array}{l}\text { The increase in drill diameter contact surface between the bone and } \\
\text { the drill increases the heat. }\end{array}$ \\
\hline Gupta et al. [42] & $\begin{array}{l}\text { The authors found that with increase in the diameter, cutting } \\
\text { temperature increased significantly. }\end{array}$ \\
\hline
\end{tabular}

With smaller or sharper $\left(\leq 90^{\circ}\right)$ point angle, drill bit 'stabs' in material easier, and 'walking' of the drill on the curved bone surface is minimized. Using sharper point angle, the drill temperature is higher on a small surface in the first moments of drilling, because of a relatively small percentage of cutting lip involved in cutting action. Drills with a larger or 
blunter $\left(>90^{\circ}\right)$ point angle accomplish a full contact of the cutting lip and the bone earlier. Generally, drills with larger point angle are more suitable for hard materials, and those with smaller angles for softer materials like bones [43]. Smaller point angles cause elliptic bores and therefore the drill should be ground to this point angle. This phenomenon of elliptic holes has not been reported in the case with $60^{\circ}$ point angle.

Drill wear is another parameter that influences the increasing of temperature. Matthews and Hirsch [35] suggested that bone temperature increases with the multiple uses of the drill. The authors confirmed that the use of drill more than 40 times can lead to an increase in temperature and causes important wear. The study of Allan et al. [44] observed a significant change in temperature due to the amount of wear during drilling of the porcine mandibles in vitro. In the literature, there is no exact information about the uses of drill repeatedly.

According to Karaca et al. [45], TiBN coated drills caused higher temperatures than uncoated ones. To overcome the high temperature during drilling, two drills with different geometrical shapes were designed by using superhard materials are tested in the study of Li et al. [46]. Under $500 \mathrm{rpm}$, the temperature was $33.5^{\circ} \mathrm{C}$ during drilling using the brazed step drill and it was $42.9^{\circ} \mathrm{C}$ using brazed twist drill.

\subsection{Irrigation}

Water jet represents one of the small amounts of tools capable to satisfy rigid requirements even in the field of orthopaedic surgery $[47,48]$. Irrigation has increasingly gained popularity in surgical treatment $[49,50,51,52]$. Orthopaedic surgeons may irrigate to dissipate heat from drilling.

During drilling, two methods internal and external cooling are used for the supply of coolant. Internal irrigation involves feeding of the coolant to the drill tip through the tubules in the drill shaft. In closed type internal irrigation, the coolant move along conjoined through the tunnels inside the drill and back to the central heat exchanger. In open type internal irrigation, the coolant flows of through the tunnels in the drill and exits from the opening at the drill tip [53]. Contrariwise, the external cooling involves feeding the coolant to the surface of the drill at the entry point. In order to reduce the friction during drilling, a 
lubrication have been used. Matthews and Hirsch proved the cooling is highly effective in limiting the maximum temperature elevations [35]. Haider et al. investigates the effects of external and internal cooling. They concluded that external irrigation is more effective whereas internal irrigation in the depth. Kalidindi found that the external cooling reduces the temperature generated during drilling [34].

In the field of neurological surgery, bone removal is an essential step. High-speed grinding generates heat, which can be an important factor in cranial nerve lesions. In acoustic Schwannoma resection, for example, it is well-known that during drilling of the porus acousticus the avoidance of heating is essential in order to limit damage to the facial and acoustic nerves. High-speed grinding can result in not only neural tissue damage, but also lead to bone necrosis, especially within the skull base [54, 55]. Kondo et al. [30] demonstrated that the maximum bone temperature reached a threshold of $43^{\circ} \mathrm{C}$ during diamond wheel grinding, despite irrigation of the saw blade as well as the drill with cold saline or ringer solution during drilling. According to the authors, some nerves are hypersensitive to cold irrigation and can benefit by having the irrigation gently. According to Tamai et al. [56], the number of injured nerves increases over time as the duration of temperature fluctuations increases. Forty percent of nerves subjected to temperature fluctuations exhibit histological injury seven days postoperatively. The temperature of $48.9^{\circ} \mathrm{C}$ can have the same physiological effect as cut severing a nerve. According to $\mathrm{Hou}$ et al. [57], the normal saline spray cooling has the best cooling effect, while air-cooling is the poorest. Sasaki et al. [58] applied another technique, namely the pressure-induced saline jet spray, for high-speed grinding wheels. The results report a $14-30 \%$ reduction using the jet spray technique compared to flood irrigation. Zhang et al. [50] compared the use of cryogenic saline mist to the conventional saline irrigation, in neurosurgical bone grinding to prevent osteonecrosis. Experimental results showed that a pre-cooling effect of the cryogenic mist helps reducing the initial temperature of bone. Despite the known deleterious effects of heat induction during bone drilling, there is no systematic method in common usage during neurosurgical procedures to present or even monitor this hazard.

\subsection{D Simulation for Osteonecrosis: Benefits and limits}


Numerical simulations appear as a valuable tool either to predict a priori the final bone temperature or to provide real-time temperature values during drilling. The choice of the appropriate software and of the material properties of each layer of the bone are critical and must be carefully identified to get reliable results. Several numerical models can achieve the complex task of simulating the human soft tissues and modelling the extreme complexity of tissue behavior. The numerical results first appeared to quite satisfy due to the modeling (linear elasticity, the problem of contact between drill and bone). Although these software tools do not replace experimental testing, they provide a valuable and rapidly evolving option for evaluating implant designs at an early stage of the test, allowing the effects of uncertainty and variability to be assessed [60]. Using Finite Element Analysis (FEA) can be considered as a solution to estimate the parameters of drilling in order to prevent the problem of osteonecrosis [61,62].These recent advances are illustrated in Figure. 1.

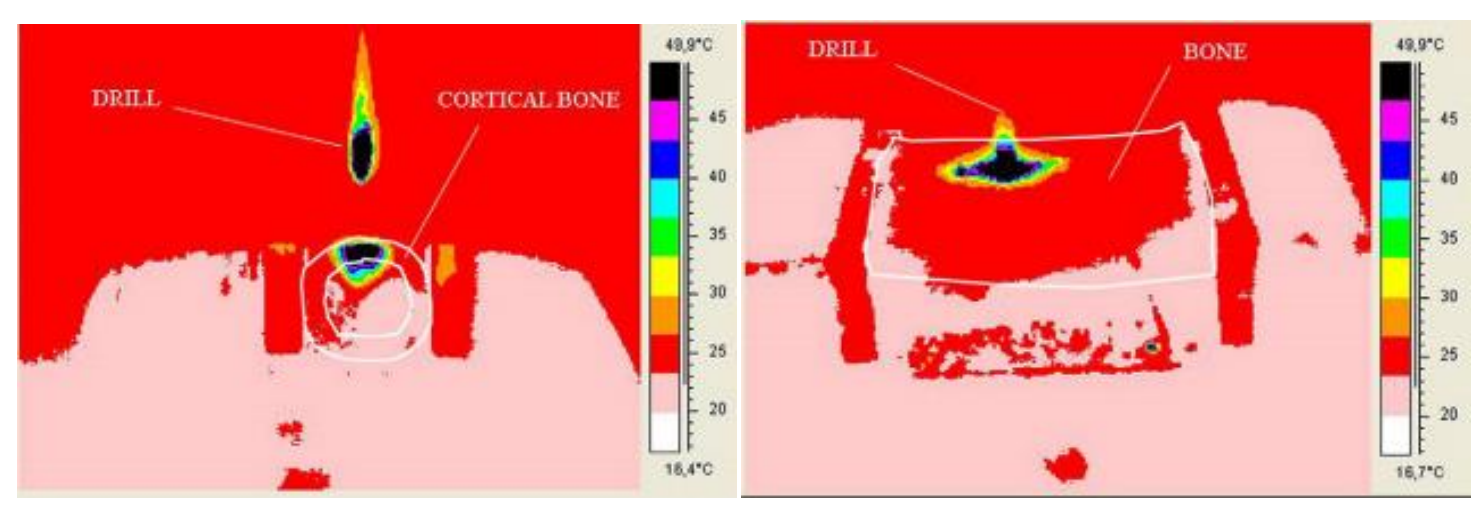

Fig. 1. Numerical simulation of the temperature field in a bone when drilling by Augustin et al. [53]

Mediouni et al. [1] provided interesting results, which compared fairly well to other FEA results. The authors study orthopedic drilling in an attempt to prevent osteonecrosis by defining the ideal drill speed, advance rate and manual pressure to apply. FEA can provide an understanding of the temperature in each level various segments of bone (trabecular or cortical). FEA helps to establish three drilling parameters such as speed of drill bit, feed rate and the forces applied by surgeons. The FEA knowledge can be carried over to the bone drilling surgical setting for optimal drilling technique application avoiding bone thermal necrosis. 


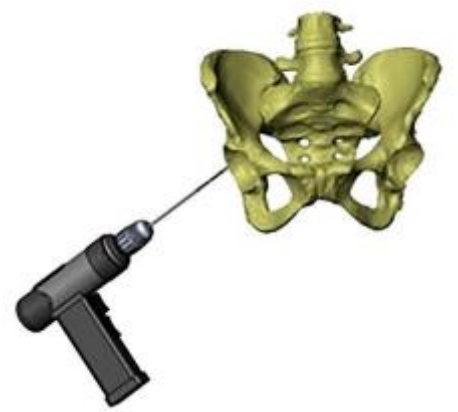

(a)
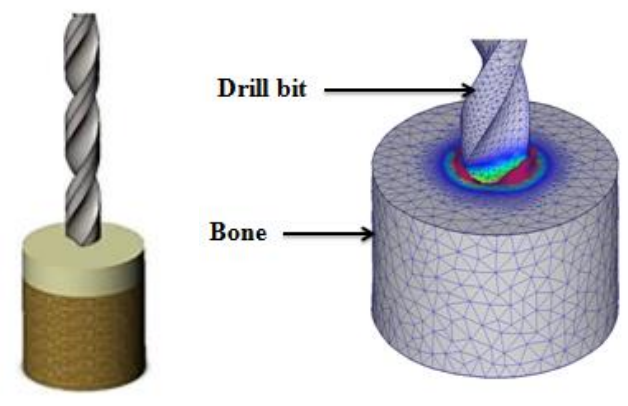

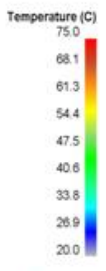

(b)

Figure 3: (a) 3D simulation of drilling of acetabular bone, (b) pelvic model and FEA defined variables to reduce heat generation and its consequence (threshold is $50^{\circ} \mathrm{C}$ ), bone necrosis. FEA data has two never before reported findings. (1) When drilling $3 \mathrm{~mm}$ of cortical bone at a constant rotation of $600 \mathrm{rev} / \mathrm{min}$. feeding 1 $\mathrm{mm} / \mathrm{sec}$ produces a force of 50-80 Newton $(\mathrm{N})$ and $75^{\circ} \mathrm{C}$ temperature, and (2) Reducing the feeding speed to $0.1 \mathrm{~mm} / \mathrm{sec}$, the temperature is reduced to $39^{\circ} \mathrm{C}$, with constant axial force and rotation of $600 \mathrm{rev} / \mathrm{min}$. from [1]

Numerical simulations may yield reliable results only if the material parameters and the motion and loading parameters are provided precisely. However, the parameters related to biological tissues, in particular bone, have a wide range of possible values. Moreover, modeling by FEA requires the selection of an adequate mathematical model that characterizes the right behavior of the materials. These models exist for various materials, such as bone, skin, muscles: as an example, for hyperelastic materials, one can cite NeoHookean, Mooney-Rivlin or Ogden models, each of these models having their own limits of applicability. This requires adjusting the parameters of the various models to match the experimental data. The selection of the appropriate model for the materials along with the successful fitting of the deformation curves is an important step towards the reliable simulation of the full problem. Coupling FEA with Computational Fluid Dynamics calculations will enable to model the drilling process and the fluid flow due to bone irrigation. A better knowledge of the temporal and spatial evolutions of the bone temperature would be gained. At the present time, such simulations are still missing. The modern requirements for a medical instrument are such that this tool should provide the same qualitative result of its application for the patient, regardless of the experience and skills of the surgeon. The tool in the hands of either a beginner or an experimented surgeon should provide an equal qualitative result, safe for the patient. This leads engineers 
to create "smart" tools that do not allow a mistake to be made. For example, when drilling bone, an intelligent drill system could inform the surgeon that the temperature in the drilling zone exceeds a critical value and that thermal osteonecrosis may occur. Simulations using the FEA is a safe way to anticipate the result of an instrument's impact on a given material. Drilling with the same parameters may be safe for one patient, but dangerous for another as the properties of bone may change.

\section{Towards Smart Orthopaedic Drill: More precision, accuracy and success}

With the advances of technologies, it is possible to re-enforce the accuracy and the efficiency of the bone drilling. In addition, in some cases, due to the long period of operations, surgeons may get tired and loose a portion of the energy and ability to focus, which could be dangerous for the patient health. The need for more accurate, precise and efficient tools and equipment is required. The orthopaedic field may gain benefit from the emergence of smart technologies also known as the Internet of Things. Many surgical robotic systems were successful over the past decades including the widely used Da Vinci surgical robot made by Intuitive Surgical Inc. Orthopaedic surgeons could potentially benefit from robotic or partially autonomous assistants already used in minimally invasive surgery (MIS) [63].

Figure 2 shows a simplified scheme of how the system will look together with the sequence of actions. Based on the diagnostic of the patient and the previous operation data, the main server of the drill will perform the data analysis first before drawing conclusions. Based on those conclusions, the server sends the appropriate actions to the intelligent drill. In realtime applications, if the server found that some parameters exceed critical values that could damage the bone tissue, action like stopping the drill rotor could be done. In the following section, we will classify the actions to be taken based on the learning model.

Bloomquist et al. [64] discussed a stop device, removing the high plunge depth variability from the sensory control of the operator. It remains a mechanical tool and so it relays on the surgeon's abilities too. Choi et al. [63] developed a novel smart surgical navigation system for intramedullary nailing in orthopaedic surgery. They stated that "Using a handleintegrated laser guidance module, the system can target a drill insertion point onto the skin, 
indicating an accurate target position to perpendicularly access an invisible distal hole". It appeared as a very accurate method, but the drilling process is still based on the surgeon's experience.

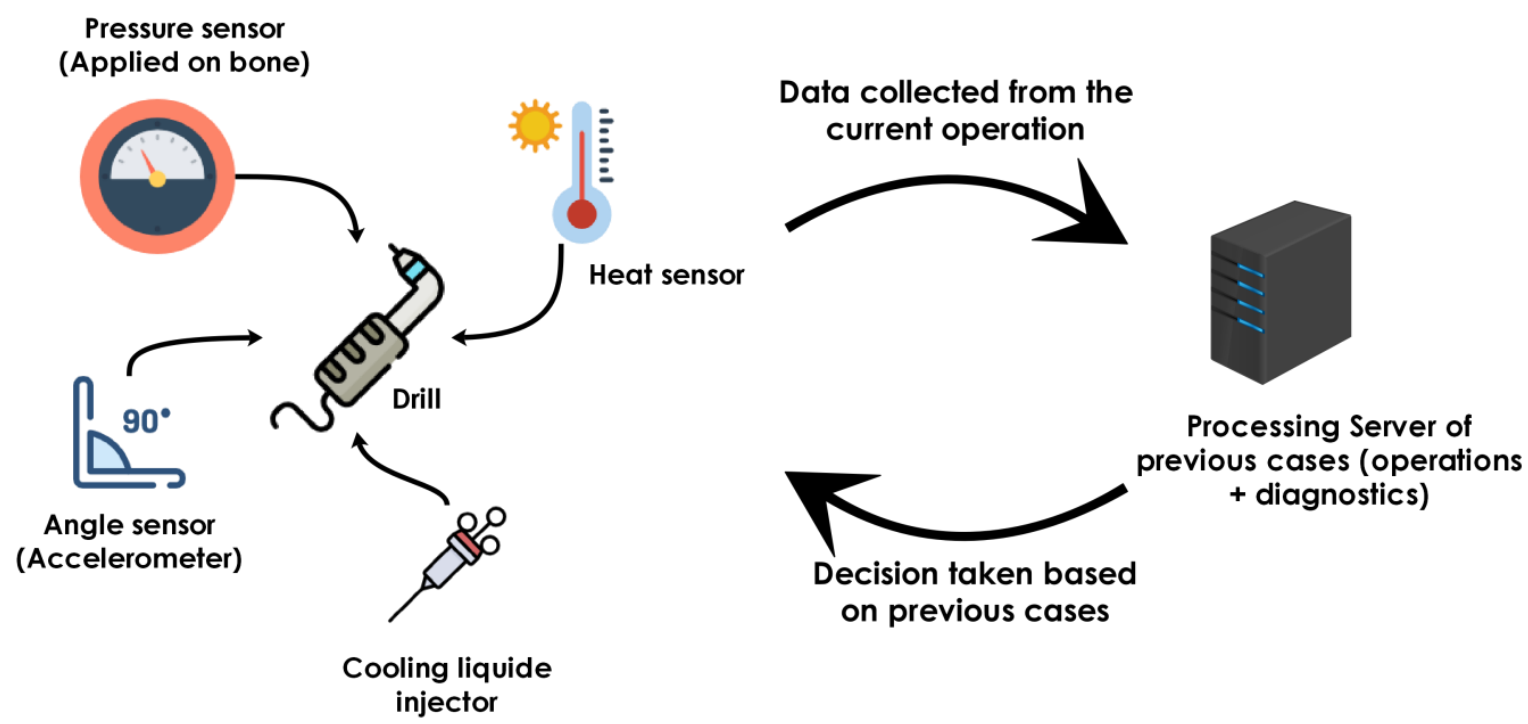

Fig. 2. A simplified scheme of how the orthopaedic drill system will look together with the sequence and actions.

Recent advances in Augmented Reality can take data from MRI scan and overlay an MRI image of the patient's bone during surgery. Wearing a head mounted display (HMD) orthopaedic surgeons could improve accuracy with guidance from the MRI data during surgery. With an image processing camera system, a computer controlled surgical guidance system could measure the angle of the drill and make corrections to more perfectly align the drill with the patient's bone from MRI data. These intelligent advances could prevent injury to the patient by reducing failure and complication rates. It would lead to enhanced recovery, so the patients can be discharged earlier, which will save money for the health service.

We could imagine the design of a new generation of orthopaedic drills that include multiple sensors and actuators to assist and help the surgeons to achieve the bone's operations with more precision and less issues and faults. With a simple temperature probe attached or not to the drill system, one could indirectly measure, for example, the bone temperature at any location using an algorithm similar to the one developed by Hafid and Lacroix [65]. These 
authors developed indeed an inverse heat transfer algorithm and applied it successfully to predict the thermal properties of tumors during cryosurgery. In the present case, one could directly use this algorithm to evaluate the thermal properties of the bone indeed adapt it to get its mechanical properties.

The new drill would be able to gather and save data from any past operations and use them in future ones through machine-learning tools. Supervised learning and neural networks are efficient tools to build models based on the patient diagnostics and the operation results. Mediouni et al. [1] proposed data analysis and highlighted the relevant parameters that should be taken into account to properly drill bones. The drills can process these data and assist the surgeons based on the current data collected from the current operation and the history of the data during similar medical interventions.

This new generation will embed an accelerometer to gather the data about the angle, the power applied by the surgeon and the orientation and a heat sensor to collect all the data about the temperature and make the cooling process optimal.

\section{Conclusion}

This article has summarized several recent and important advances in thermal necrosis prevention. Recently there is an increased progress in the prevention of osteonecrosis and new techniques appeared including computer simulation models. While representing a watershed moment in the evolution of orthopaedic and neurological procedures, the highspeed drill in typical usage remains essentially unchanged over the past quarter century. However, the negative effects of heat-induction during drilling are well-known, simple and effective methods for monitoring and cooling in real-time are still not in widespread usage to date. Ample technology now exists to change the drilling paradigm and interdisciplinary research efforts are still required to improve patient outcomes. Various future intelligent advances, which could improve bone-drilling surgery, were outlined. These recent advances are expected to prevent injury to the patient by reducing failure and complication rates of orthopedic surgery. It would lead to enhanced recovery.

\section{Disclosure statement}

The authors declare that there is no conflict of interest 


\section{References}

[1] Mediouni M., Schlatterer D.R., Khoury A., Von Bergen T., Shetty S.H., Arora M., Dhond A., Vaughan N., Volosnikov A. (2017) Optimal parameters to avoid thermal necrosis during bone drilling: A finite element analysis. Journal of Orthopaedic Research, 35 (11), 2386-2391.

[2] Mediouni M., Schlatterer D.R., Madry H., Cucchiarini M., Rai, B. (2018) A review of translational medicine. The future paradigm: how can we connect the orthopedic dots better? Current Medical Research and Opinion, 34 (7), 1217-1229.

[3] Steinberg M.E., Mont M.A. (2001) Osteonecrosis. In M. Chapman (Ed.), Chapman's orthopaedic surgery (3rd ed.), vol. 3, pp. 3263-3308, Philadelphia: Lippincott Williams \& Wilkins.

[4] Lee J, Chavez CL, Park J. Parameters affecting mechanical and thermal responses in bone drilling: A review. Journal of biomechanics. 2018 Mar 1.

[5] Drilling of Bone: Practicality, Limitations and Complications Associated with Surgical Drill-Bits. N Bertollo, WR Walsh, Prince of Wales Hospital, Sydney, Australia.

[6] Ishida K., Tsumura N., Takayama K., Fukase N., Kitagawa A., Chin T., Iguchi T., Matsumoto T., Kubo S., Kurosaka M., Kuroda R. (2011). Thermal necrosis after simultaneous tibial osteotomy and total knee arthroplasty using press-fit extension-stem. Knee surgery, sports traumatology, arthroscopy: official journal of the ESSKA, 19, 112114.

[7] Pandey R.K., Panda S.S. (2013) Drilling of Bone: A Comprehensive Review, Journal of Clinical Orthopaedics and Trauma, 4 (1), 15-30.

[8] Stahel P.F., Alfonso N.A., Henderson C., Baldini T. (2017) Introducing the "BoneScrew-Fastener" for improved screw fixation in orthopedic surgery: a revolutionary paradigm shift? Patient Safety in Surgery, 11, 6.

[9] Gao L., Goebel L.K.H., Orth P., Cucchiarini M., Madry H. (2018) Subchondral drilling for articular cartilage repair: a systematic review of translational research. Disease Models \& Mechanisms, 11(6), 034280.

[10] Vaughan R.C., Peyton F.A. (1951). The influence of rotationalspeed on temperature rise during cavity preparation. J Dent Res 30, 737-744. 
[11] Reingewirtz Y., Szmukler-Moncler S., Senger B. (1997). Influence of different parameters on bone heating and drilling time in implantology. Clinical Oral Implants 8, 189-197.

[12] Zhao G., Yong-Ming Y., Kaneki M., Bonab A.A., Tompkins R.G., Fischman A.J. (2015) Simvastatin reduces burn injury-induced splenic apoptosis via downregulation of the TNF- $\alpha / \mathrm{NF}-\kappa \mathrm{B}$ pathway. Annals of Surgery, 261 (5), 1006-1012.

[13] Huang S., Gateley D., Moss A.L. (2007) Accidental burn injury during knee arthroscopy. Arthroscopy, 23(12), 1363, e1-e3.

[14] Hsu Y.-L., Lee S.-T., Lin H.-W. (2001) A modular mechatronic system for automatic bone drilling. Biomedical Engineering: Applications, Basis and Communications, 13 (04), $168-174$.

[15] Schroeder J.E., Weil Y.A., Khoury A., Liebergall M., Mosheiff R. (2010) Thermal tibial osteonecrosis: A diagnostic challenge and review of the literature, Injury, 41 (2), 235238.

[16] Singh G, Gahi A, Jain V, Gupta D. An investigation on thermal necrosis during bone drilling. International Journal of Machining and Machinability of Materials. 2016;18(4):341-9.

[17] Singh G, Jain V, Gupta D, Ghai A. Optimization of process parameters for drilled hole quality characteristics during cortical bone drilling using Taguchi method. Journal of the mechanical behavior of biomedical materials. 2016 Sep 1;62:355-65. [18] Singh G, Jain V, Gupta D. Comparative study for surface topography of bone drilling using conventional drilling and loose abrasive machining. Proceedings of the Institution of Mechanical Engineers, Part H: Journal of Engineering in Medicine. 2015Mar;229(3):22531.

[19] Singh G, Jain V, Gupta D, Sharma A. Parametric effect of vibrational drilling on osteonecrosis and comparative histopathology study with conventional drilling of cortical bone. Proceedings of the Institution of Mechanical Engineers, Part H: Journal of Engineering in Medicine. 2018 Oct;232(10):975-86.

[20] Eriksson A.R., Albrektsson T., Albrektsson B. (1984) Heat caused by drilling cortical bone. Temperature measured in vivo in patients and animals. Acta Orthopaedica Scandinavica, 55, 629-631. 
[21] Bachus K.N., Rondina M.T., Hutchinson D.T. (2000) The effects of drilling force on cortical temperatures and their duration: an in vitro study. Medical Engineering and Physics, 22(10), 685-691.

[22] Toews A.R., Bailey J.V., Townsend H.G.G., Barber S.M. (1999) Effect of feed rate and drill speed on temperatures in equine cortical bone. American Journal of Veterinary Research, 60, 942-944.

[23] Matthews L.S., Green C.A., Goldstein S.A. (1984) The thermal effects of skeletal fixationpin insertion in bone. Journal of Bone and Joint Surgery, 66 (7), 1077-1083.

[27] Yacker M.J., Klein M. (1996) The effect of irrigation on osteotomy depth and bur diameter. The International Journal of Oral \& Maxillofacial Implants, 11, 634-638.

[28] Matthews L.S., Hirsch C. (1972) Temperature measured in human cortical bone when drilling. The Journal of Bone and Joint Surgery - American Volume, 54, 297-308.

[29] Eriksson R.A., Adell R. (1986) Temperatures during drilling for the placement of implants using the osseointegration technique. Journal of Oral and Maxillofacial Surgery, 44, 4-7.

[30] Kondo S., Okada Y., Iseki H., Hori T., Takakura K., Kobayashi A., Nagata H. (2000). Thermological study of drilling bone tissue with a high-speed drill. Neurosurgery 46, 1162 1168.

[31] Hillery HT, Shuaib I. Temperature effects in drilling of human and bovine bone. J Mater Process Technol. 1999;92e93: 302e308.

[32] Wiggins KL, Malkin S. Drilling of bone. J Biomech. 1976;9:553-559

[33] Cardioli G, Majzoub Z. Heat generation during implant site preparation: an in vitro study. J Oral Maxillofac Implants. 1997;12:186-193.

[34] Kalidindi V. Optimization of Drill Design and Coolant Systems During Dental Implant Surgery. MS thesis, University of Kentucky; 2004.

[35] Matthews Larry S, Hirsch C. Temperatures measured in human cortical bone when drilling. J Bone Joint Surg Am. 1972;54:297-308.

[36] Augustin G, Davila S, Mihoci K, Udiljak T, Vedrina DS, Antabak A. Thermal osteonecrosis and bone drilling parameters revisited. Arch Orthop Trauma Surg. 2008;128:71e77 
[37] Sharawy M, Misch CE, Weller N, Tehemar S. Heat generation during implant drilling: the significance of the motor speed. J Oral Maxillofac Surg. 2002;60:1160e1169

[38] Boyne PJ. Histologic response of bone to sectioning by highspeed rotary instruments. J Dent Res. 1964;45:270e276

[39] Moss RW. Histopathologic reaction of bone to surgical cutting. Oral Surg Oral Med Oral Pathol. 1964;17:405e414

[40] Iyer S, Weiss C, Mehta A. Effect of drill speed on heat production and the rate and quality of bone formation in dental implant osteotomies. Part I: relationship between drill speed and heat production. Int J Prosthodont. 1997;10(5):411e414.

[41] Reingewirtz Y, Szmukler-Moncler S, Senger B. Influence of different parameters on bone heating and drilling time in implantology. Clin Oral Implants Res. 1997;8:189e197. [42] Vishal Gupta, Pulak M. Pandey, Asit R. Mridha, Ravi K. Gupta. Effect of Various Parameters on the Temperature Distribution in Conventional and Diamond Coated Hollow Tool Bone Drilling: A Comparative Study. Procedia Engineering 184 (2017) 90-98.

[43] Nicky Bertollo, William Robert Walsh. Drilling of Bone: Practicality, Limitations and Complications Associated with Surgical Drill-Bits. INTECH Open Access Publisher, 2011.

[44] Allan W, Williams ED, Kerawala CJ. Effects of repeated drill use on temperature of bone during preparation for osteosynthesis self-tapping screws. Br J Oral Maxillofac Surg. 2005;43(4):314e319.

[45] Karaca, F., Aksakal, B., Kom, M., 2011. Influence of orthopaedic drilling parameters on temperature and histopathology of bovine tibia: an in vitro study. Medical Engineering \& Physics 33, 1221-1227.

[46] Changhe Li \& Huayang Zhao \& Hongliang Ma \& Yali Hou \& Yanbin Zhang \& Min Yang \& Xiaowei Zhang. Simulation study on effect of cutting parameters and cooling mode on bone-drilling temperature field of superhard drill. Int J Adv Manuf Technol (2015) 81:2027-2038.

[47] Kl'oc J. Solutions disorders hip replacements, leading to reoperation. PhD Thesis, Technical University of Košice, 2009.

[48] Hloch S., Valíček J., Kozak D. (2011) Preliminary results of experimental cutting of porcine bones by abrasive waterjet, Tehnicki vjesnik-Technical Gazette, 18 (3), 467-470. 
[49] Hreha P., Hloch S., Magurova D., Valicek J., Kozak D., Harnicarova M., Rakin M. (2010) Water jet technology used in medicine. Tehnicki Vjesnik, 17, 237-240.

[50] Oertel J., Gaab M.R., Warzok R., Piek J. (2003) Waterjet dissection in the brain: review of the experimental and clinical data with special reference to meningioma surgery. Neurosurgical Review, 26, 168-174.

[51] Rau H.G., Duessel A.P., Wurzbacher S. (2008) The use of water-jet dissection in open and laparoscopic liver resection. HPB, 10, 275-280.

[52] Yu S., Gao Z., Lin C., Sun X., Men C., Yu L., Yang D. (2014) Waterjet dissection for partial nephrectomy without hilar clamping in a porcine model. International Surgery, 99, $677-680$.

[53] Augustin G., Zigman T., Davila S., Udilljak T., Staroveski T., Brezak D., Babic S. (2012). Cortical bone drilling and thermal osteonecrosis. Clinical biomechanics, 27(4), 313-325.

[54] Spetzler R.F., Kalani M.Y.S., Nakaji P., Yagmurlu K. (2017) Color Atlas of Brainstem Surgery, Thieme: New York. pp. 115-117.

[55] Hosono N., Miwa T., Mukai Y., Takenaka S., Makino T., Fuji T. (2009) Potential Risk of Thermal Damage to Cervical Nerve Roots by a High-speed Drill. Journal of Bone and Joint Surgery British, 91 (11), 1541-1544.

[56] Tamai K., Suzuki A., Takahashi S., Akhgar J., Rahmani M.S., Hayashi K., Ohyama S., Nakamura H. (2017) The incidence of nerve root injury by high speed drill can be reduced by chilled saline irrigation in a rabbit model. Bone Joint Journal - British Volume, 99, 554-560.

[57] Hou Y., Li C., Ma H., Zhang Y., Yang M., Zhang X. (2015) An Experimental Research on Bone Drilling Temperature in Orthopaedic Surgery. The Open Materials Science Journal, 9, 178-188.

[58] Sasaki M., Morris S., Goto T., Iwatsuki K., Yoshimine T. (2010) Spray-irrigation System Attached to High-speed Drills for Simultaneous Prevention of Local Heating and Preservation of a Clear Operative Field in Spinal Surgery. Neurologia Medico-chirurgica, 50(10), 900-904.

[59] Zhang L., Tai B.L., Wang A.C., Shih A.J. (2013) Mist cooling in neurosurgical bone grinding. CIRP Annals - Manufacturing Technology, 62, 367-370. 
[60] Mediouni M., Schlatterer D.R. (2017) Orthopaedic tumors: What problems are we solving, and are universities and major medical centers doing enough? Journal of Orthopaedics 14, 319-32.

[61] Sezek S., Aksakal B., Karaca F. (2012) Influence of drill parameters on bone temperature and necrosis: A FEM modelling and in vitro experiments. Computational Materials Science, 60, 13-18.

[62] Mediouni M., Volosnikov A. (2015). The trends and challenges in orthopaedic simulation. Journal of Orthopaedics, 12(4), 253-259.

[63] Choi J., Kim J., Hwang J.Y., Je M., Kim J.Y., Kim S.Y. (2017) A novel smart navigation system for intramedullary nailing in orthopedic surgery. PLoS ONE, 12(4), e0174407.

[64] Bloomquist A., Bousley G., LaCroix A., Murphy K. (2016) Orthopedic Drill Stop Device. BME Design Project, University of Wisconsin, Madison.

[65] Hafid M., Lacroix M. (2017) An Inverse Heat Transfer Algorithm for Predicting the Thermal Properties of Tumors during Cryosurgery, International Journal of Biomedical and Biological Engineering, 11 (6), 352-360.

[66] Elliot-Lewis EW, Mason AM, Barrow DL. Evaluation of a new bipolar coagulation forceps in a thermal damage assessment. Neurosurgery (2009); 65:1182-7.

[67] Sindou M, Mercier P. Microvascular decompression for hemifacial spasm: surgical techniques and intraoperative monitoring. Neurochirurgie (2018); 64: 133-43.

[68] Aydin k, Cokluik C, Ayas B, Onger ME, Keskin I, Ozyasar A, Aslan H, Kaplan s. Hippocampal cell loss after an anterior and posterior anastomotic vein occlusion model in rats. Int J Dev Neurosi (2011); 29:717-22.

[69] Saleh TM, Cribb AE, Connell BJ. Reduction in infarct size by local estrogen does not prevent autonomic dysfunction after stroke. Am J Physiolo Regul Integr Comp Physiol (2001); 281: R2088-95. 